\title{
Protest Response and Willingness to Pay for Culturally Significant Urban Trees: Implications for Contingent Valuation Method
}

\section{Citation:}

Lo, A.Y. and Jim, C.Y. (2015) Protest Response and Willingness to Pay for Culturally Significant Urban Trees: Implications for Contingent Valuation Method. Ecological Economics, 114, p.5866.

\begin{abstract}
The Contingent Valuation Method (CVM) could assist green-space planning, management and appreciation by assigning a monetary value to urban trees. However, the use of CVM is limited by its inherent methodological weaknesses. A critical concern is the existence of a large proportion of survey respondents providing zero willingness-to-pay (WTP) and that these responses are not amenable to economic theory - known as 'protest' responses. Censoring protest responses from further treatment is a common practice, which warrants reconsideration in light of our CVM survey results. The survey involved 800 residents requested to state their WTP for preserving the culturally significant stonewall trees in urban Hong Kong. About 28\% of respondents returned a zero WTP. For all respondents the strength of protest beliefs was assessed, and the relationship between protest beliefs and WTP were examined. Our analysis produced contradictory results: some protest items varied negatively with WTP as expected, but other items increased with it. Respondents' stated positive WTP harbored latent protest beliefs which are related to non-economic preference. The findings stand at odds with the assumptions underlying the censoring treatment and raise questions about the validity of WTP estimates. These methodological implications should be taken into account in using CVM.
\end{abstract}

Keywords: Contingent Valuation Method; protest response; willingness to pay; environmental valuation; urban trees; Hong Kong 


\section{Introduction}

Non-market valuation is an economic approach for assigning monetary value to environmental goods and services that are not directly traded in markets. It can put a price on non-marketed natural landscapes and public open spaces, and has great potential for informing decision-making in environmental planning and management (Börger, 2013; Jim and Chen, 2009; Vandermeulen et al., 2011). The Contingent Valuation Method (CVM) is one of the most popular valuation techniques. It is particularly useful for assessing the existence values that people assign to natural elements in cities, including urban trees and green spaces (Bernath and Roschewitz, 2008; Brander and Koetse, 2011; Jim and Chen, 2006; Lo and Jim, 2010; Majumdar et al., 2011; Tyrväinen and Väänänen, 1998; Vesely, 2007). This article addresses a critical but rather neglected methodological issue in the use of CVM for environmental planning and management.

The CVM involves direct inquiry into people's preferences for environmental goods or services (Mitchell and Carson, 1989). It is usually implemented through questionnaire surveys designed in accordance with economic principles. In CVM, an institutional context is created in which a hypothetical environmental change takes place and an implicit trade-off between personal income and environmental quality is required. Individuals who participate in a CVM survey are asked to indicate the maximum amount of money they are willing to pay to prevent the negative environmental change (WTP). The stated WTP is taken as relating to the value of the underlying environmental services or goods and used in cost-benefit analysis upon aggregation.

However, the CVM has been criticized as methodologically flawed (Gatzweiler, 2014; Lo and Spash, 2013; Spash, 2008; Spash et al., 2009; Whitehead, 2014). One key limitation is the existence of a large proportion of respondents in the sample providing zero WTP and that these responses are not amenable to economic theory - commonly known as 'protest' responses (Jorgensen and Syme, 2000; Jorgensen et al., 2001; Meyerhoff et al., 2014a; Meyerhoff and Liebe, 2006, 2010; Meyerhoff et al., 2014b). Censoring and excluding protest responses from further analysis is a common practice in order to avoid conceptual inconsistencies and underestimation of aggregate WTP estimates. This standard procedure has been challenged and contested in earnest. As suggested by Jorgensen and Syme (2000) and Meyerhoff and Liebe (2006), the main argument against arbitrary exclusion is that protest responses are related to, and 
systematically dependent on, other forms of response that are included in subsequent WTP estimation. Censoring one type of response but not another type that represents the same underlying attitude is methodologically inappropriate and probably conceptually untenable.

Supporting evidence on the systematic relationship between protest response and stated WTP could illuminate the application of CVM in environmental planning and management. The standard practice of censorship and exclusion warrants reconsideration in this light. To the extent that such correlation exists, WTP estimates should be seen as an indication of political, social, or moral sentiments, rather than economic preferences, and therefore fail to satisfy the economic assumptions underlying the CVM and represent economic values (Lo and Spash, 2013; Spash, 2007). Consequently, stated WTP would need to be understood as a non-economic construct, creating both theoretical and methodological difficulties for CVM applications.

This article aims to empirically demonstrate the systematic relationship between protest beliefs and WTP. More importantly, it shows that both positive and negative relationships exist, challenging the usual expectation that respondents who react to the WTP question in a negative way would return a zero or low WTP (Jorgensen and Syme, 2000; Meyerhoff and Liebe, 2006; Grammatikopoulou and Olsen, 2013). It is based on the results of a CVM survey involving 800 residents of Hong Kong and featuring a unique form of urban trees dwelling on old masonry walls with exceptional merits for preservation. Findings are useful for CVM practitioners, environmental planners and managers, nature conservationists, and decision-makers to improve understanding of this common valuation technique.

The following section further elaborates on the methodological issues regarding CVM, followed by a description of the study area and the form of urban trees being investigated. Research methods are then introduced and results presented. The implications of findings for CVM application are discussed in the concluding section.

\section{Protest Response and the Use of CVM}

Assumptions about protest response require further clarification in order to address the methodological quandary. The CVM is used to elicit people's preferences, expressed in the form 
of WTP bids. Protest responses, however, stem from the respondent's failures to express preferences in a prescribed way that is consistent with economy theory. According to Strazzera et al. (2003), such responses can be grouped into two categories: 1) the respondent cannot agree to the method of preference elicitation; and 2) the respondent is concerned about fairness of the requested payment (i.e. WTP or WTA). Those responses driven by the respondent's economic constraints or failures to derive utility from protecting the environmental goods or services specified in the CVM scenario are classified as ‘true zero’ bids and not protests.

To identify protest responses, respondents who state a zero bid ('zero bidders') are probed to specify underlying reasons. Usually, a list of possible reasons is presented in the form of debriefing questions for selection by respondents. Examples include: 'it is unfair for me to pay', 'the government should use taxpayers money to pay for it', 'I don't want to put a dollar value on protecting plants and animals', 'Not enough information is given', 'I object to the way the question is asked', 'the money collected won't make a difference', 'I don't have faith in the authority', and 'others should pay', etc. (adapted from Jorgensen and Syme, 2000; Jakobsson and Dragun, 2001; Meyerhoff and Liebe, 2006; Grammatikopoulou and Olsen, 2013). Respondents may be requested to nominate the most important reason for offering a zero bid or select all items that apply.

What remain contested are the ways in which the reasons for giving protest bids are understood and presented. Firstly, positive bidders are typically not subject to the debriefing questions and listed as non-protesters. The underlying economic assumption is that protest beliefs and WTP, as an expression of economic preference, are mutually exclusive. In keeping with this assumption, zero bids are often identified as either 'true' or protest zero (Ferreira and Gallagher, 2010; Grammatikopoulou and Olsen, 2013; Jakobsson and Dragun, 2001; Xu et al., 2003). However, the dichotomy between 'economic' (true) and 'non-economic' (protest) expressions is far from clear. Jorgensen and Syme (2000) and Meyerhoff and Liebe (2006) have shown that those respondents who stated a positive WTP held some degree of protest beliefs. The interdependence between the two forms of expressions calls into question the strict demarcation of positive WTP from protest beliefs.

Another usual assumption is that protest bidders are less willing to pay, if not refusing to do so at all. Jorgensen and Syme (2000) and Meyerhoff and Liebe (2006) have identified a 
negative relationship between the level of WTP and the strength of protest beliefs, implying that high WTPs contain some non-economic elements. However, a more surprising and troubling observation, reported by Grammatikopoulou and Olsen (2013, p. 239), is a positive relationship between WTP and protest: 'protest respondents represent individuals that on average would be willing to pay a higher amount for the area's preservation than those who provide valid statements to the valuation question'. Conceptually this is possible because protest beliefs may represent an attitude toward paying for a course of action for protecting the environment, i.e. a pro-environment attitude. This observation seriously undermines the established position that WTP represents economic preference, because protest responses are defined as an expression of non-economic preference. Further evidence, however, is needed to verify Grammatikopoulou and Olsen's (2013) claim and make suggestions as to how WTP should be understood.

These two methodological issues raise question about the standard procedure of censoring protest responses. This procedure is premised upon the assumption that protest observations are a random portion of the sample that can be excluded without affecting results (Grammatikopoulou and Olsen, 2013). As Strazzera et al. (2003, p. 462) explain, 'removing protest responses can be valid if the group of protesters is not significantly different from the remainder of the sample'. Otherwise systematic relationship between protest beliefs and WTP implies that protest bidders are likely to state a WTP value different from the rest of the sample. The use of CVM in line with the standard procedure would be subject to significant sample selection bias.

The research reported in this paper solicited evidence on the systematic relationship. A CVM survey was conducted to explore if 1) WTP is a function of protest beliefs and, if so, 2) in what direction they are linked to each other. The following sections describe research methods.

\section{Methods}

Study area

The questionnaire survey was administered in Hong Kong, which is a typical compact city situated at the southern coast of China. The city holds 7.18 million people in only $1,108 \mathrm{~km}^{2}$ of 
land, yielding an average population density of 6,330 persons $/ \mathrm{km}^{2}$, which is among the highest in the world. Built-up areas are squeezed into merely 23\% of the land (Planning Department, 2013). Furthermore, the land is beset by serious topographical constraints, with some 80 per cent at > $100 \mathrm{~m}$ elevation associated with steep slopes that are difficult for development. Land constraints have constituted a chronic physical limitation to green space and tree growth in urban Hong Kong.

Despite the lack of plantable space, vegetation in the city has found unexpected sites for spontaneous growth. Urban Hong Kong has a unique ecological habitat in the form of stoneretaining walls. Some of the oldest representatives exceed 100 years; they were established during the early colonial years and are concentrated in the urban core developed in the $19^{\text {th }}$ and early $20^{\text {th }}$ century, notably north Hong Kong Island and Kowloon Peninsula. Some are situated at roadsides and adjacent to main streets, whereas others are sequestered behind buildings and in obscure lanes. The oldest walls, which were constructed using traditional Chinese techniques, have masonry blocks with irregular shape and size and a rough surface, many unmortared gaps between individual stones, and existence of soil in the crevices and behind the stone façade for plants to grow without human assistance or intervention (Jim and Chen, 2010). Most of these vertical, dry and sterile surfaces in cities are apparently inhospitable for plant species. Yet the method and style of the construction of these old stone-retaining walls have permitted spontaneous colonization by plants, including large trees up to $20 \mathrm{~m}$ tall (Jim, 2013a) (Figures 1 and 2).

Vertical wall surfaces in built-up areas present a rocky-cliff analog niche for trees to colonize (Jim, 2014). The stone-retaining walls in Hong Kong, holding soil with moisture supply behind the masonry façade, offer favorable structural-cum-ecological conditions for tree growth (Jim, 1998, 2010). The humid-subtropical climate of Hong Kong with Banyan trees (Ficus species with strangler-fig growth habit) plays a crucial role in widespread wall colonization. These walls support some 1275 trees and occur in densely built-up areas dominated by artificial surfaces with few undeveloped areas. Most of these walls have $1-3$ trees, with an exception one with 50, and have 2 - 5 tree species, the richest being 14 (Jim, 2010). Considering the exceptionally harsh and stressful wall habitat, the number of tree species and individual trees and their total biomass are notable. 
Old stone walls in urban Hong Kong signify a cultural asset inherited from a bygone era with high historical values. Mature trees dwelling on these walls denote nature partnering with culture in a serendipitous coalition, giving them exceptional ecological, landscape and cultural merits. The walls-cum-vegetation, many exceeding 100 years old, furnish a precious naturalcum-cultural heritage and decorate some otherwise drab neighborhoods. A regrettable reality, however, is that these wall trees have become a threatened heritage, due to poor maintenance, destructive stabilization associated with mounting safety concern, and widespread urban redevelopment (Jim, 1998, 2010). New retaining structures are invariably made of reinforced concrete and do not permit tree growth. The shrinking legacy has attracted considerable public attention from local communities during the past decade.

Valuation techniques, such as the CVM, could play an important role in supporting attempts to preserve the endangered heritage. The CVM is well-suited for capturing non-use values, notably existence and bequest values that characterize this unique form of urban trees. Although a few CVM studies have been conducted for urban trees and green spaces in Hong Kong or cities with similar characteristics (Chen and Jim, 2010; Jim and Chen, 2006; Lo and Jim, 2010), no attempt has been made to measure this special natural-cum-cultural heritage in monetary terms. Valuing this important heritage, however, may attract a large number of protest response, because putting a price on such a culturally and ecologically important public asset is not a common way for expressing environmental values and preferences among lay public (Clark et al., 2000). Consequently, the CVM exercise may be vulnerable to the methodological issues raised above (Lo, 2012, 2014a; Lo and Jim, 2010). An empirical investigation into the implications of protest response was conducted to explore the conceptual robustness of CVM in this context.

\section{Questionnaire design}

A structured questionnaire survey was administered in Hong Kong to elicit people's preference for stonewall trees. The survey instrument was built upon the questionnaire used for our previous research project (Lo and Jim, 2010, 2012), with some modifications to strengthen the focus on stonewall trees. It included a CVM component and a set of debriefing questions. The WTP 
question began with a factual description of stonewall trees. Pictures showing two local examples were presented (Figures 1 and 2). Respondents indicated if they had any prior knowledge about this form of trees.

A hypothetical scenario was then read out by the interviewer: 'The Hong Kong government decided to remove all stonewall trees to make space for redevelopment. If a nongovernmental organization proposed that all these trees and the surrounding structures be acquired for the purpose of preservation, how much would you be willing to pay to support this action? You would be assured that all money you paid would be devoted to the preservation of stonewall trees, and the size of your payment would determine how many trees would be preserved'. Respondents were requested to consider how much they personally were willing to pay each month over the next year. Payment vehicle was not specified to minimize impacts on the tendency to protest (Meyerhoff and Liebe, 2010).

Monetary values were elicited through a payment card that consisted of 13 WTP levels, namely, \$0, \$10, \$15, \$20, \$30, \$50, \$80, \$100, \$150, \$200, \$300, \$500 (note: HKD/USD = 1/7.8). Respondents were allowed to nominate a preferred amount if they were unable to choose one from the payment card. A ‘don’t know / refuse to answer' option was available. This elicitation approach has the strengths of its alternatives, namely, dichotomous choice and openended question. The dichotomous choice approach restricts respondent's choice to one or two WTP levels and is vulnerable to the anchoring effect (Mitchell and Carson, 1989), whereas the open-ended approach might attract many protest responses (Meyerhoff and Liebe, 2010). The payment card approach can reduce cognitive burdens on respondents without unnecessarily constraining their choice.

After the WTP question, all respondents articulated their protest beliefs by responding to eight debriefing questions, regardless of their WTP decision. This non-traditional procedure, pioneered by Jorgensen and Syme (2000) and Meyerhoff and Liebe (2006), was premised upon the assumption that positive WTPs and protest responses are not mutually exclusive. As shown in Table 1, these questions represented different aspects of concern about the WTP question, such as the hypothetical scenario, the approach of valuation, fairness, and information. Although being used for representing protest beliefs, some of these items can be articulated in terms of social psychological or political concepts. For example, the statement suggesting that most 
people will not pay for tree conservation $(\mathrm{H})$ measures attitude toward conditional cooperation (Liebe et al., 2011), while other statements are related to the level of trust in powerful agents (e.g. property developers) in the society (B and C) (Lo, 2014b). The choice of questions or statements was informed by, and adapted from, various sources, notably Jorgensen and Syme (2000) and Meyerhoff and Liebe (2006) and Grammatikopoulou and Olsen (2013), and directly referred to the preceding WTP question. Responses were measured by a five-point Likert scale, ranging from 'strongly disagree' to 'strongly agree' (the higher the score, the stronger the protest belief).

In addition, the questionnaire included a five-item scale to measure residents' attitude toward stonewall trees to examine our suggestion that protest beliefs represent a proenvironmental attitude that strengthens the willingness to pay for tree conservation. The five survey statements are listed in the Appendix, and full details about this composite scale are reported elsewhere (Lo and Jim, 2015). The questionnaire also collected respondents' socioeconomic information, including their education level, sex, age, personal income and length of residence in the current district.

\section{Survey administration}

Face-to-face interviews were conducted in public areas of 13 local council districts ${ }^{1}$. The sample was distributed amongst these districts approximately according to local population size. One major public park or multiple neighborhood parks were selected from each of the selected districts as study sites, based on proximity to housing clusters, pedestrian traffic, and feasibility for conducting street survey ${ }^{2}$. In Hong Kong, public areas offer more opportunities to approach residents for interviews than their household units. Most people in Hong Kong live in high-rise residential buildings guarded by security checkpoints. Unsolicited visits are discouraged and estate managers tend to deny access to households for conducting non-government surveys. Our previous experience suggests that both residents and estate managers were more comfortable with conducting interviews in public areas than in the household units (Lo and Jim, 2010, 2012).

\footnotetext{
${ }^{1}$ including the Central and Western, Southern, and Eastern Districts in Hong Kong Island; Kowloon City, Kwun Tong, Sham Shui Po, Wong Tai Sin, and Yau Tsim Mong Districts in Kowloon; Kwai Tsing, North, Sha Tin, Sai Kung, Tuen Mun Districts in New Territories.

${ }^{2}$ In urban Hong Kong, some public parks are not suitable for conducting intercept surveys, due to the limited park area surrounded by tight pedestrian passages and a mix of noise, security, and hygienic problems.
} 
A quasi-random sampling strategy was adopted. The random procedure was operated by inviting one out of every three park visitors to participate in the research. Those who were aged over 18 years old and lived in the district where the interview took place were selected as respondents. In addition, a sampling quota was determined by age distribution in the district concerned, based on the latest available census data. Trained interviewers were instructed to approach a particular age group when the sampling quota for the remaining age groups had been exhausted. Our sampling strategy produced a larger proportion (37.5\%) of residents from Hong Kong Island, where the majority of stonewall trees are situated, than the actual share of population in this region (18\%) in 2011 (Census and Statistics Department, 2012). We did not pursue demographic representativeness of data, but focused on the statistical relationship between WTP and protest beliefs.

A university-based research service provider was appointed to administer the survey. Several undergraduate students with prior interview experience were recruited as interviewers and coached in the procedures and etiquette of the survey. Fieldwork was supervised by a senior staff member and each completed questionnaire was checked in situ by the interviewer. The questionnaire and the valuation scenario were tested by several individuals and refined based on their feedbacks. The main survey started in October 2012 and ended in February 2013.

\section{Results}

\section{Descriptive analysis}

A total of 800 face-to-face interviews were completed in the selected sites. A comparable number (787) of individuals contacted refused to participate or terminated the interview halfway through. This yielded a completion rate of $50.4 \%{ }^{3}$. In the sample, the number of male respondents (53.2\%) exceeded females (46.8\%) (Table 2). Slightly more than half (52.3\%) aged below 45. Forty-one per cent of respondents held a tertiary degree. For personal income, 31.2\%

\footnotetext{
${ }^{3}$ Response rate is $60.7 \%$ if those who agreed to participate but were not qualified or their age group had exceeded the quota were taken into account (417 individuals).
} 
of respondents earned more than $\mathrm{HK} \$ 15,000^{4}$. Nearly two-third (63\%) had heard of stonewall trees prior to participating in the survey. The average length of residence was 18.3 years.

Of the 800 respondents, 771 selected a WTP from the payment card or nominated a preferred amount. Twenty-nine individuals were unable to choose or refused to answer. As a common practice (Spash, 2006), these 29 responses were equated to missing data and censored from the analysis of WTP bids. The average WTP was HK\$60.9 per month and the median was HK\$20 per month. The estimation excluded two outliners with a nominated WTP of HK\$5,000. More than one-fourth (216, or 28.1\%) of respondents returned a zero WTP. The distribution of WTP bids is displayed in Figure 3.

Protest beliefs were factor analyzed (Table 3). Principal Component Analysis with varimax rotation extracted three factors, which are labelled as 'Approach', 'Scenario', and 'Fairness'. The first factor consisted of two statements expressing resistance to the proposed approach for preserving stonewall trees, i.e. valuing these trees in monetary terms and acquiring surrounding areas. The second factor included four statements related to the hypothetical scenario of valuation. The first three concerned the specific components of the valuation case, i.e. the government or property developers should pay for preserving these trees rather than the public, and redevelopment is not an acceptable reason for cutting down these trees, whereas the fourth one requested clarification about the scenario. The third factor described fairness issues about the request for payment. The two statements in this factor expressed discontent with the idea that the respondent had to assume payment responsibility for preservation these trees and that most other people would not pay.

None of the three factors yielded a satisfactory alpha value (all lower than 0.7 ) and therefore additive scales were not used in the subsequent analysis. All of these protest belief variables correlated with WTP bids, but the direction of effects varied (correlation coefficients are displayed in the Appendix). This was further examined in a regression analysis presented below.

\footnotetext{
${ }^{4}$ In Hong Kong, the monthly wage level at the $50^{\text {th }}$ percentile was HK\$14,900 in 2013 (Census and Statistics Department, 2013)
} 


\section{Regression analysis}

Ordered regression analyses were used to examine the survey data (Agresti and Finlay, 1997; O'Connell, 2006). All WTP categories presented in Figure 3 were included in the regression model, without censoring zero WTP. Test of parallel lines yielded satisfactory results $\left(\chi^{2}=63.85\right.$, $\mathrm{p}>$.05), suggesting that the proportional odds assumption was not rejected ${ }^{5}$. Results suggest that protest belief items created differential impacts on the level of stated WTP (Table 4). Concern about the proposed approach for preserving stonewall trees negatively influenced WTP (Statements A and E), whereas concern about the hypothetical scenario had positive effects (Statements C, D and F). Only one fairness item, i.e. perceived lack of similar action by other people (Statement $\mathrm{H}$ ), negatively drove WTP to a significant degree, probably due to concern about free-riding as payment vehicle was not specified in our study. This means that respondents who considered the attempted valuation as a flawed approach or the payment unfair tended to indicate a lower WTP, but those who disputed the portrayed scenario offered a higher WTP. Younger and better-off individuals were more likely to pay more. Other personal characteristics variables achieved little statistical significance.

Given the relatively large proportion of zero bids in the full sample, it was deemed to be appropriate to conduct separate analyses for zero and positive WTP responses. The regression was re-run with positive WTP only. Test of parallel lines yielded satisfactory results $(\chi 2=41.68$, $\mathrm{p}>$.05). As shown in Table 5, protest belief items lost significance in the alternative model. Only one approach item (Statement A) and one fairness item (Statement H) predicted WTP. Scenario protest became statistically unimportant. Personal income retained its explanatory power, but age did not. These results suggest that protest beliefs did not offer a strong explanation for the variations in the level of positive WTP.

Nevertheless, protest beliefs account for the likelihood of stating a positive WTP. The dependent variable in the third regression model, presented in Table 6, was a binary variable that takes ' 1 ' if the respondent indicated a positive WTP, and otherwise ' 0 '. In this model, the approach (Statements $\mathrm{A}$ and E) and fairness (Statement $\mathrm{H}$ ) items reduced the probability of

\footnotetext{
${ }^{5}$ The test of parallel lines tests whether the one-equation model is valid. The null hypothesis states that the slope coefficients in the model are the same across response categories (and lines of the same slope are parallel). The test statistics shows that the null hypothesis is not rejected and that the assumption holds. Source: UCLA Institute for Digital Research and Education (http://www.ats.ucla.edu/stat/spss/output/ologit.htm)
} 
returning a positive WTP, whereas scenario protest beliefs (Statements C, D and F) increased with it. This shows that although protest responses, particularly scenario protest, did not significantly contribute to the level of positive WTP, they explained the likelihood of paying for the preservation of stonewall trees.

The positive effects may stem from pro-environmental attitude. To examine this possible explanation, an additional analysis was conducted, using the composite scale measuring attitude toward stonewall trees. We found that this measure correlated with the four scenario protest statements (B, C, D and F) in a positive way (all p <.01), but not other protest items (see Appendix). This suggests that those individuals who favor stonewall trees are more likely to protest against the CVM scenario. Scenario protest response may be driven by pro-tree attitude.

\section{Discussion}

This research addressed two hypotheses through a CVM survey about old stonewall trees in urban Hong Kong. Based on the assumption that protest response and expression of WTP are not mutually exclusive, this study recorded both protest beliefs and positive WTP and investigated the ways in which they were related. Furthermore, protest beliefs are defined as a non-economic reason for individuals to state a zero WTP although their true WTP is higher than zero. In the light of the hypothesized linkage between protest response and expression of WTP, this study examined if they are related to each other in the same direction.

Our results indicate a systematic relationship between protest beliefs and WTP, controlling variables representing personal characteristics. The results corroborate the findings of Jorgensen and Syme (2000) and Meyerhoff and Liebe (2006) that protest beliefs correlate with WTP. The fact that some individuals who agree to pay for a course of action for protecting the environment (in this case, stonewall trees) hold protest beliefs is not a random observation. The observed systematic relationship contradicts the common assumption that only those who are not willing to pay would protest against the request for payment. As Meyerhoff and Liebe (2006, p. 592) conclude, 'those who are willing to pay also hold significant protest beliefs that influence

their decisions'. The methodological implication is that respondents expressing positive WTP may harbor latent protest beliefs that can inform policy formulation and decision making, thus 
censoring holders of protest beliefs who state a zero WTP but not those who state a positive WTP cannot be justified. The common practice of censoring zero bids by identifying protesters calls for re-examination.

Both positive and negative relationships between protest beliefs and WTP are identified. The usual expectation is a negative one (Jorgensen and Syme, 2000; Meyerhoff and Liebe, 2006; Grammatikopoulou and Olsen, 2013): respondents who react to the WTP question in a negative way are expected to return a zero or low WTP. In our study this is found to be true as far as the act of valuing or paying is concerned.

A positive relationship, however, also exists - between scenario protest and WTP. In our study, three of the scenario protest items increased with the tendency to state a WTP. These items denote scepticism toward the proposed action of removing some culturally significant urban trees and demand for more information about it before making a decision. Unlike the other two categories of protest response (i.e. approach and fairness), scenario protesters articulate a concern about the proposed removal of trees, and not mainly about the act of valuing or paying per se. The tendency to protest against the hypothetical scenario is associated with positive attitudes toward stonewall trees. These scenario protestors are likely to be more knowledgeable about and supportive of tree conservation initiative. Scenario protest beliefs therefore connote a higher level of concern, which results in higher WTP bids. The co-existence of positive and negative effects offers new insights into the ways in which protest beliefs and WTP are understood by economists and CVM practitioners.

Scenario protest and WTP represent a common disposition, i.e. stonewall trees are a valuable public asset and worth preserving. This view is supported by the widely accepted position that stated WTP is an expression of attitude (Kahneman and Knetsch, 1992; Kahneman et al., 1999; Kotchen and Reiling, 2000). Protest and WTP may vary in the same direction to the extent in which the expression of protest belief and WTP are construed as different facets of the same attitude toward, for example, protecting stonewall trees from permanent damage. These results create conceptual difficulties in understanding WTP in economic terms. Protest response has been defined as an expression of preference that is not amenable to economic assumptions and, therefore, protest zero bids are conventionally excluded from the estimation of aggregate WTP and subsequent cost-benefit analysis (Spash, 2006; Spash et al., 2009). In contrast, positive 
WTP indicates willingness to trade-off money for securing an expected utility gain from environmental improvement and can be couched in economic terms (Hanley and Spash, 1993; Mitchell and Carson, 1989). Our finding that scenario protest and WTP vary in the same direction raises an important methodological issue, i.e. whether WTP should be construed as a function of economic or non-economic preferences.

Our second and third regression models could help address this issue. Scenario protest belief explained the likelihood of stating a positive WTP, but had limited impacts on the level of WTP. This suggests that scenario protest affected the decision to contribute or not, but not how much to pay. The latter is subject to economic considerations, such as budget constraint. Consistent with usual expectations, personal income predicted the level of WTP, but failed to account for the likelihood of paying. These results corroborate Liebe et al.'s (2011, p. 124) finding that "income does not significantly affect in-principle WTP but is a main predictor of WTP amount". On the other hand, the decision to state a positive WTP is a function of protest response, which is understood as an expression of non-economic preference.

Results of our study contribute to the literature by confirming the systematic relationship between protest response and stated WTP and demonstrating the existence of both positive and negative relationships. The findings stand at odds with the assumptions underlying the CVM and raise questions about the validity of WTP estimates in the presence of a large number of protest zero bids. Censoring protest bids can be seen as valid to the extent that these observations are a random segment of a given sample and the group of protesters is not significantly different from the remainder of the sample (Strazzera et al., 2003; Grammatikopoulou and Olsen, 2013). The systematic relationship between protest response and stated WTP implies non-randomness. Consequently the standard censoring procedure could create bias in sample selection and lead to biased WTP estimates (either underestimation or overestimation). Conceptually, the findings also raise issues about the conventional economic interpretation of WTP estimates (Lo and Spash, 2013; Spash et al., 2009) and support the view that WTP represents an attitude, rather than economic preference (Jorgensen et al., 2001; Kahneman and Knetsch, 1992; Kahneman et al., 1999; Kotchen and Reiling, 2000). 


\section{Conclusions}

Urbanization has displaced a great deal of green spaces during the course of development (Jim, 2000, 2013b; Jim and Shan, 2013). In compact cities, the shrinkage of vegetated areas and poor management of old heritage trees are a regrettable outcome that urban planners and managers struggle to avoid. A handful of tree species managed to enlist stone-retaining walls as a viable ecological habitat for growth. In urban Hong Kong, such old masonry walls are a cultural asset inherited from a bygone era with high historical values. Mature trees dwelling on these walls denote a seamless synergy between nature and culture in a serendipitous alliance. Stonewall trees in urban Hong Kong have exceptional merits for preservation.

The CVM could support the planning and management of urban trees by eliciting people's preference and assigning a monetary value to them. Although this technique offers useful information for decision making, it has a number of methodological limitations that urban planners and managers should be aware of. Putting a price on culturally and ecologically significant natural assets, such as stonewall trees, is not a common way for expressing environmental preferences among the general public (Clark et al., 2000). As a result, many individuals fail to state a monetary value in CVM surveys or offer a zero WTP. Some of these zero responses violate economic assumptions (i.e. protest response) and are usually excluded from WTP estimation.

Environmental planning practitioners interested in using the CVM should be alerted to the pitfall of conventional procedure of excluding protest zero bids against the payment request. Censoring protest responses lacks justification if they correlate with the level of WTP. These responses may represent a non-random segment of the sample. Censoring them without proper methodological reasoning may create bias in sample selection and result in underestimation or overestimation of aggregate WTP values, depending on which form of protest beliefs prevails in the given context. Moreover, this study produced contradictory results, challenging the assumption that individuals who protest against aspects of the CVM tend to return a zero or low WTP. Evidence suggests that those who indicate a positive WTP may also hold strong protest beliefs. This raises question about the degree to which stated WTP represents economic preference, particularly when the sample of a CVM survey includes a large number of zero WTP observations which signifies the tendency to protest against request for payment. 
Practitioners are suggested to measure the strength of various protest beliefs when using the CVM. It is important to ascertain the relationship between WTP and protest, and address the abovementioned methodological issues, before adopting the controversial censoring procedure. If a significant number (> 50\%) of protest responses is recorded, the conceptual justifications for using the CVM should be reviewed and alternative techniques should be considered. Future research might explore the effects on the WTP-protest relationship of different payment vehicles, such as taxes or utility bills, and elicitation approaches, such as dichotomous choice (Meyerhoff and Liebe, 2008). Excluding zero WTP from the full sample alters the sample structure and might distort the bid curve analysis. Further efforts are needed to examine the methodological implications of this treatment. 


\section{References}

Agresti, A., Finlay, B., 1997. Statistical Methods for the Social Sciences. Prentice Hall, New Jersey.

Bernath, K., Roschewitz, A., 2008. Recreational benefits of urban forests: explaining visitors' willingness to pay in the context of the theory of planned behavior. Journal of Environmental Management 89, 155-166.

Börger, T., 2013. Keeping up appearances: Motivations for socially desirable responding in contingent valuation interviews. Ecological Economics 87, 155-165.

Brander, L.M., Koetse, M.J., 2011. The value of urban open space: Meta-analyses of contingent valuation and hedonic pricing results. Journal of Environmental Management 92, 2763-2773.

Census and Statistics Department, 2012. Hong Kong in Figures. Hong Kong SAR Government, Hong Kong.

Census and Statistics Department, 2013. 2013 Report on Annual Earnings and Hours Survey Hong Kong Special Administrative Region Hong Kong.

Chen, W.Y., Jim, C.Y., 2010. Resident motivations and willingness-to-pay for urban biodiversity conservation in Guangzhou (China). Environmental Management 45, 1052-1064.

Clark, J., Burgess, J., Harrison, C.M., 2000. "I struggled with this money business": respondents' perspectives on contingent valuation. Ecological Economics 33, 45-62.

Ferreira, S., Gallagher, L., 2010. Protest responses and community attitudes toward accepting compensation to host waste disposal infrastructure. Land Use Policy 27, 638-652.

Gatzweiler, F.W., 2014. Reframing the Value of Nature: Biological Value and Institutional Homeostasis. Environmental Values 23, 275-295.

Grammatikopoulou, I., Olsen, S.B., 2013. Accounting protesting and warm glow bidding in Contingent Valuation surveys considering the management of environmental goods - An empirical case study assessing the value of protecting a Natura 2000 wetland area in Greece. Journal of Environmental Management 130, 232-241.

Hanley, N., Spash, C.L., 1993. Cost-Benefit Analysis and the Environment. Edward Elgar, Aldershot, England

Jakobsson, K., Dragun, A., 2001. The Worth of a Possum: Valuing Species with the Contingent Valuation Method. Environmental and Resource Economics 19, 211-227.

Jim, C.Y., 1998. Old stone walls as an ecological habitat for urban trees in Hong Kong. Landscape and Urban Planning 42, 29-43.

Jim, C.Y., 2000. The urban forest programme in the heavily built-up milieu of Hong Kong. Cities 17, 271283.

Jim, C.Y., 2010. Old Masonry Walls as Ruderal Habitats for Biodiversity Conservation and Enhancement in Urban Hong Kong, in: Müller, N., Werner, P., Kelcey, J.G. (Eds.), Urban biodiversity and design. Wiley-Blackwell, Chichester, UK

$\mathrm{Jim}$, C.Y., 2013a. Drivers for colonization and sustainable management of tree-dominated stonewall ecosystem. Ecological Engineering 57.

$\mathrm{Jim}$, C.Y., 2013b. Sustainable urban greening strategies for compact cities in developing and developed economies. Urban Ecosystems 16, 741-761.

Jim, C.Y., 2014. Ecology and conservation of strangler figs in urban wall habitats. Urban Ecosystems 17, 405-426.

Jim, C.Y., Chen, W.Y., 2006. Recreation-amenity use and contingent valuation of urban greenspaces in Guangzhou, China. Landscape and Urban Planning 75, 81-96.

Jim, C.Y., Chen, W.Y., 2009. Ecosystem services and valuation of urban forests in China. Cities 26, 187194. 
Jim, C.Y., Chen, W.Y., 2010. Habitat effect on vegetation ecology and occurrence on urban masonry walls. Urban Forestry \& Urban Greening 9, 169-178.

Jim, C.Y., Shan, X., 2013. Socioeconomic effect on perception of urban green spaces in Guangzhou, China. Cities 31, 123-131.

Jorgensen, B.S., Syme, G.J., 2000. Protest responses and willingness to pay: attitude toward paying for stormwater pollution abatement. Ecological Economics 33, 251-265.

Jorgensen, B.S., Wilson, M.A., Heberlein, T.A., 2001. Fairness in the contingent valuation of environmental public goods: Attitude toward paying for environmental improvements at two levels of scope. Ecological Economics 36, 133-148.

Kahneman, D., Knetsch, J.L., 1992. Valuing public goods: the purchase of moral satisfaction. Journal of Environmental Economics and Management 22, 57-70.

Kahneman, D., Ritov, I., Schkade, D., 1999. Economic preferences or attitude expressions?: an analysis of dollar responses to public issues. Journal of Risk and Uncertainty 19, 203-235.

Kotchen, M.J., Reiling, S.D., 2000. Environmental attitudes, motivations, and contingent valuation of nonuse values: a case study involving endangered species. Ecological Economics 32, 93-107.

Liebe, U., Preisendörfer, P., Meyerhoff, J., 2011. To Pay or Not to Pay: Competing Theories to Explain Individuals' Willingness to Pay for Public Environmental Goods. Environment and Behavior 43, 106130.

Lo, A.Y., 2012. The encroachment of value pragmatism on pluralism: The practice of the valuation of urban green space using stated-preference approaches. International Journal of Urban and Regional Research 36, 121-135.

Lo, A.Y., 2014a. More or Less Pluralistic? A Typology of the Remedial and Alternative Perspectives on Monetary Valuation of the Environment. Environmental Values 23, 253-274.

Lo, A.Y., 2014b. The right to doubt: climate-change scepticism and asserted rights to private property. Environmental Politics 23, 549-569.

Lo, A.Y., Jim, C.Y., 2010. Willingness of residents to pay and motives for conservation of urban green spaces in the compact city of Hong Kong. Urban Forestry \& Urban Greening 9, 113-120.

Lo, A.Y., Jim, C.Y., 2015. Community attachment and resident attitude toward old masonry walls and associated trees in urban Hong Kong. Cities 42, 130-141.

Lo, A.Y., Spash, C.L., 2013. Deliberative monetary valuation: In search of a democratic and value plural approach for environmental policy. Journal of Economic Surveys 27, 768-789.

Majumdar, S., Deng, J., Zhang, Y., Pierskalla, C., 2011. Using contingent valuation to estimate the willingness of tourists to pay for urban forests: A study in Savannah, Georgia. Urban Forestry \& Urban Greening 10, 275-280.

Meyerhoff, J., Boeri, M., Hartje, V., 2014a. The value of water quality improvements in the region BerlinBrandenburg as a function of distance and state residency. Water Resources and Economics 5, 49-66.

Meyerhoff, J., Liebe, U., 2006. Protest beliefs in contingent valuation: explaining their motivation. Ecological Economics 57, 583-594.

Meyerhoff, J., Liebe, U., 2008. Do protest responses to a contingent valuation question and a choice experiment differ? Environmental and Resource Economics 39, 433-446.

Meyerhoff, J., Liebe, U., 2010. Determinants of protest responses in environmental valuation: A metastudy. Ecological Economics 70, 366-374.

Meyerhoff, J., Mørkbak, M., Olsen, S., 2014b. A Meta-study Investigating the Sources of Protest Behaviour in Stated Preference Surveys. Environmental and Resource Economics 58, 35-57.

Mitchell, R.C., Carson, R.T., 1989. Using Surveys to Value Public Goods: the Contingent Valuation Method Resources for the Future, Washington, D.C.

O'Connell, A.A., 2006. Logistic regression models for ordinal response variables SAGE, London. 
Planning Department, 2013. Planning statistics: Land utilization in Hong Kong. Hong Kong Government, Hong Kong. Available at: http://www.pland.gov.hk/pland_en/info_serv/statistic/landu.html (Accessed on June 9, 2014).

Spash, C.L., 2006. Non-economic motivation for contingent values: Rights and attitudinal beliefs in the willingness to pay for environmental improvements. Land Economics 82, 602-622.

Spash, C.L., 2007. Deliberative monetary valuation (DMV): issues in combining economic and political processes to value environmental change. Ecological Economics 63, 690-699.

Spash, C.L., 2008. How much is that ecosystem in the window? The one with the bio-diverse trail. Environmental Values 17, 259-284.

Spash, C.L., Urama, K., Burton, R., Kenyon, W., Shannon, P., Hill, G., 2009. Motives behind willingness to pay for improving biodiversity in a water ecosystem: economics, ethics and social psychology. Ecological Economics 68, 955-964.

Strazzera, E., Genius, M., Scarpa, R., Hutchinson, G., 2003. The Effect of Protest Votes on the Estimates of WTP for Use Values of Recreational Sites. Environmental and Resource Economics 25, 461-476.

Tyrväinen, L., Väänänen, H., 1998. The economic value of urban forest amenities: an application of the contingent valuation method. Landscape and Urban Planning 43, 105-118.

Vandermeulen, V., Verspecht, A., Vermeire, B., Van Huylenbroeck, G., Gellynck, X., 2011. The use of economic valuation to create public support for green infrastructure investments in urban areas. Landscape and Urban Planning 103, 198-206.

Vesely, E.-T., 2007. Green for green: the perceived value of a quantitative change in the urban tree estate of New Zealand. Ecological Economics 63, 605-615.

Whitehead, M., 2014. Editorial: Price of Everything/Value of Nothing. Environmental Values 23, 249-252.

$\mathrm{Xu}$, Z., Cheng, G., Zhang, Z., Su, Z., Loomis, J., 2003. Applying contingent valuation in China to measure the total economic value of restoring ecosystem services in Ejina region. Ecological Economics 44, 345-358. 


\section{$\underline{\text { Figure captions }}$}

Figure 1. This old stone retaining wall at Hollywood Road in Central District in Hong Kong is associated with the heritage site of one of the earliest schools. It has been colonized by a series of strangler figs that can grip the artificial cliff with strong and sprawling roots which extend through the joints between masonry blocks to reach the soil lying behind the wall.

Figure 2. A row of magnificent Chinese Banyans (Ficus microcarpa) hangs gracefully on this old stone retaining wall in Pokfulam District in Hong Kong. The land in front of the wall is designated as a public children's playground, hence the stonewall trees can escape from the pressure of redevelopment or maintenance of vehicular clearance. 
Table 1 Descriptive statistics for protest beliefs

\begin{tabular}{|c|c|c|c|}
\hline Statement & $\%$ Agree $^{\wedge}$ & Average $^{\#}$ & S.D. \\
\hline $\begin{array}{l}\text { A. Acquiring the areas around wall trees is not an effective } \\
\text { way for conservation }\end{array}$ & 53.3 & 3.38 & 0.88 \\
\hline $\begin{array}{l}\text { B. The government should use taxpayers money to protect } \\
\text { these trees. There is no need to raise funds from the public }\end{array}$ & 74.5 & 3.83 & 0.86 \\
\hline $\begin{array}{l}\text { C. Property developers gain significant profits from urban } \\
\text { redevelopment. They should pay for conservation of these } \\
\text { trees }\end{array}$ & 75.8 & 3.90 & 0.89 \\
\hline $\begin{array}{l}\text { D. Removing these trees for the sake of urban redevelopment } \\
\text { is unacceptable }\end{array}$ & 54.5 & 3.47 & 0.95 \\
\hline E. I refuse to measure the value of wall trees in money terms & 69.9 & 3.71 & 0.81 \\
\hline $\begin{array}{l}\text { F. I need more information to decide whether to support tree } \\
\text { conservation or not }\end{array}$ & 69.9 & 3.63 & 0.91 \\
\hline G. It is unfair for me to pay for protection of these trees & 61.9 & 3.63 & 0.96 \\
\hline $\begin{array}{l}\text { H. My money won't make a difference because most people } \\
\text { won't pay anything for that }\end{array}$ & 74.4 & 3.33 & 0.89 \\
\hline
\end{tabular}


Table 2 Descriptive statistics for demographic variables

\begin{tabular}{lrr}
\multicolumn{1}{c}{ Variable } & Average & S.D. \\
\hline Sex $(1=$ male, $0=$ otherwise $)$ & 0.53 & 0.50 \\
Age $(1=$ below $45,0=$ otherwise $)$ & 0.52 & 0.50 \\
Education $(1=$ tertiary degree, $0=$ otherwise) & 0.41 & 0.49 \\
Personal income $(1=$ HK\$15,000 or more, $0=$ otherwise) & 0.31 & 0.46 \\
Prior knowledge about stonewall trees $(1=$ yes/little, $0=$ & 0.63 & 0.48 \\
otherwise) & & 12.71 \\
Length of residence in current district (number of years) & 18.30 & \\
\hline
\end{tabular}


Table 3 Factor loadings of protest belief statements

\begin{tabular}{lrrr} 
Statement & Approach & $\begin{array}{r}\text { Factor } \\
\text { Scenario }\end{array}$ & Fairness \\
\hline A: Approach ineffective & .842 & & \\
E: Approach rejected & .658 & & \\
& & & \\
B: Government's responsibility & & .536 & \\
C: Developers' responsibility & .663 & \\
D: Action unacceptable & .642 & \\
F: More information needed & .534 & \\
& & & \\
G: Unfair to me & & & .754 \\
H: Others won't pay & & & .813 \\
\hline & & & \\
Eigenvalues & 1.184 & 1.557 & 1.620 \\
\% of variance explained & 14.803 & 19.463 & 20.254 \\
\hline
\end{tabular}


Table 4 Ordered probit regression for willingness to pay for conservation of stonewall trees (all WTP categories)

\begin{tabular}{|c|c|c|c|}
\hline Variable & Coefficient & & Std. Error \\
\hline \multicolumn{4}{|l|}{ Protest belief } \\
\hline A: Approach ineffective & -.177 & $* * *$ & .046 \\
\hline E: Approach rejected & -.116 & $*$ & .052 \\
\hline B: Government's responsibility & .076 & & .050 \\
\hline C: Developers' responsibility & .224 & $* * *$ & .049 \\
\hline D: Action unacceptable & .253 & $* * *$ & .046 \\
\hline F: More information needed & .199 & $* * *$ & .047 \\
\hline G: Unfair to me & -.014 & & .051 \\
\hline H: Others won't pay & -.284 & $* * *$ & .054 \\
\hline \multicolumn{4}{|l|}{ Personal characteristics } \\
\hline Sex (male) & .074 & & .080 \\
\hline Age (below 45) & .213 & * & .096 \\
\hline Education (tertiary degree) & .064 & & .091 \\
\hline Income (HK\$15,000 or more) & .397 & $* * *$ & .089 \\
\hline Prior knowledge about stonewall trees & -.017 & & .083 \\
\hline Length of residence & .002 & & .003 \\
\hline-2 log likelihood & 2576.15 & & \\
\hline Chi-square & 205.26 & & \\
\hline$p$ & 0.000 & & \\
\hline Nagelkerke $\mathrm{R}^{2}$ & 0.25 & & \\
\hline
\end{tabular}


Table 5 Ordered probit regression for willingness to pay for conservation of stone-wall trees (positive WTP only)

\begin{tabular}{|c|c|c|}
\hline Variable & Coefficient & Std. Error \\
\hline \multicolumn{3}{|l|}{ Protest belief } \\
\hline A: Approach ineffective & $-.132 *$ & .055 \\
\hline E: Approach rejected & -.054 & .060 \\
\hline B: Government's responsibility & .059 & .060 \\
\hline C: Developers' responsibility & .105 & .060 \\
\hline D: Action unacceptable & .057 & .056 \\
\hline F: More information needed & .100 & .059 \\
\hline G: Unfair to me & .043 & .057 \\
\hline H: Others won't pay & $-.192 * *$ & .063 \\
\hline \multicolumn{3}{|l|}{ Personal characteristics } \\
\hline Sex (male) & .169 & .092 \\
\hline Age (below 45) & .154 & .110 \\
\hline Education (tertiary degree) & .029 & .102 \\
\hline Income (HK\$15,000 or more) & $.528 * * *$ & .101 \\
\hline Prior knowledge about stone-wall trees & .037 & .096 \\
\hline Length of residence & .001 & .004 \\
\hline-2 log likelihood & 1849.50 & \\
\hline Chi-square & 73.83 & \\
\hline $\mathrm{p}$ & 0.000 & \\
\hline Nagelkerke $\mathrm{R}^{2}$ & 0.13 & \\
\hline
\end{tabular}


Table 6 Binary logistic regression for willingness to pay for conservation of stonewall trees (positive WTP or otherwise)

\begin{tabular}{|c|c|c|}
\hline Variable & Coefficient & Std. Error \\
\hline \multicolumn{3}{|l|}{ Protest belief } \\
\hline A: Approach ineffective & $-.283^{* *}$ & .112 \\
\hline E: Approach rejected & $-.273 *$ & .134 \\
\hline B: Government's responsibility & .136 & .110 \\
\hline C: Developers' responsibility & $.482^{* * *}$ & .115 \\
\hline D: Action unacceptable & $.629^{* * *}$ & .108 \\
\hline F: More information needed & $.412^{* * *}$ & .107 \\
\hline G: Unfair to me & .019 & .128 \\
\hline H: Others won't pay & $-.536 * * *$ & .139 \\
\hline \multicolumn{3}{|l|}{ Personal characteristics } \\
\hline Sex (male) & .080 & .194 \\
\hline Age (below 45) & -.409 & .226 \\
\hline Education (tertiary degree) & -.203 & .224 \\
\hline Income (HK\$15,000 or more) & -.179 & .224 \\
\hline Prior knowledge about stone-wall trees & .110 & .198 \\
\hline Length of residence & .006 & .008 \\
\hline-2 log likelihood & 704.51 & \\
\hline Chi-square & 156.36 & \\
\hline $\mathrm{p}$ & 0.000 & \\
\hline Nagelkerke $\mathrm{R}^{2}$ & 0.28 & \\
\hline
\end{tabular}

$\mathrm{N}=742 .{ }^{* * *} \mathrm{p}<0.001,{ }^{* *} \mathrm{p}<0.01,{ }^{*} \mathrm{p}<0.05$ 
Appendix

Table A1 Statements measuring attitude toward stonewall trees (pro-tree attitude)

\section{Statement}

1. Stonewall trees can improve the outlook of the community

2. Stonewall trees are part of the community history that money cannot buy

3. Damage on stonewall trees is not recoverable

4. Stonewall trees are a unique urban treasure

5. Preserving stonewall trees is more important than urban redevelopment

$\alpha=0.78$. All items loaded on one factor (cut-off 0.40 ). Measured on a five-point scale: 1 = 'strongly disagree', 5 = 'strongly agree'.

Table A2 Correlation coefficients for WTP and protest beliefs

Protest belief statement

\begin{tabular}{|c|c|c|c|c|c|c|c|c|c|}
\hline \multicolumn{9}{|c|}{ Protest belief statement } & \multirow{2}{*}{$\begin{array}{l}\text { Pro-tree } \\
\text { attitude }\end{array}$} \\
\hline & $A$ & $E$ & B & $C$ & $D$ & $F$ & $\mathrm{G}$ & $\mathrm{H}$ & \\
\hline $\begin{array}{c}\text { WTP (all } \\
\text { categories) }\end{array}$ & $-.157^{* *}$ & $-.083^{*}$ & $.088^{*}$ & $.177^{* *}$ & $.234^{* *}$ & $.234^{* *}$ & $-.073 *$ & $-.231^{* *}$ & $.340 * *$ \\
\hline A & & $.191^{* *}$ & $-.077^{*}$ & -.036 & $-.073 *$ & -.043 & .041 & .016 & $-.219 * *$ \\
\hline$E$ & & & $.143^{* *}$ & $.155^{* *}$ & $.197^{* *}$ & -.031 & $.187^{* *}$ & $.235 * *$ & .018 \\
\hline B & & & & $.223 * *$ & $.202 * *$ & $.073^{*}$ & $.208^{* *}$ & $.227^{* *}$ & $.217^{* *}$ \\
\hline C & & & & & $.187^{* *}$ & $.151^{* *}$ & $.107^{* *}$ & $.107^{* *}$ & $.250 * *$ \\
\hline D & & & & & & $.124^{* *}$ & $.123^{* *}$ & .061 & $.461 * *$ \\
\hline $\mathrm{F}$ & & & & & & & -.036 & $-.133^{* *}$ & $.220 * *$ \\
\hline G & & & & & & & & $.450 * *$ & -.010 \\
\hline $\mathrm{H}$ & & & & & & & & & -.065 \\
\hline
\end{tabular}

$* * p<0.01, * p<0.05$ 